\title{
A Study to Assess the Knowledge on Computer Vision Syndrome among Bank Employees Working in Selected Banks at Mangalore with the View to Develop Self-Instruction Module
}

\author{
A. Devika \\ Department of Medical-Surgical Nursing, Bharati Vidyapeeth College of Nursing, Navi Mumbai, Maharashtra, India
}

\section{Abstract}

Introduction: It has been estimated that due to exponentially increased, usage of computers worldwide have resulted in health problems, especially ocular problems reducing quality of life and productivity of computer users, leading to financial losses.

Aim: The overall aim of the study is to assess the knowledge of bank employees regarding computer vision syndrome (CVS) and to assess of association between knowledge score among bank employees on CVS with selected demographic variables.

Materials and Methods: Descriptive survey approach with a typical descriptive design was adopted in the present study. Purposive sampling technique was used for sample selection and structured knowledge questionnaire was used to assess the knowledge of bank employee's on CVS. Reliability of the knowledge questionnaire was $r=0.78$. After data collection, the self-instruction module on CVS was distributed to bank employees to improve their knowledge.

Results: The findings of the present study reveal that the mean percentage of total knowledge score was $37.46 \%$ with mean 11.24 , median 25.5, and SD 2.58. Most (70\%) of the samples had moderate knowledge; about 30\% of them had inadequate knowledge regarding CVS. The assessment of association of knowledge among bank employees on CVS with demographic variables revealed that the presence of eye problem in the demographic variable has significant association with the level of knowledge among bank employees.

Conclusion: Overall findings revealed that majority of the bank employees had moderate and inadequate knowledge regarding CVS. Hence, it is concluded that further improvement of the knowledge of CVS is needed.

Keywords: Bank employees, computer vision, self-instruction module

\section{INTRODUCTION}

The human eye was designed for more of distance work and we sailed through centuries with minimal difficulties as the eyes could adapt to the changes in our near tasks. The transformation from hunting in the open to working on paper has been slow and gradual and put not much stress on the visual system. However, the shift from PAPER to COMPUTERS has been so rapid and strong that the eye has

Access this article online

Website: http://innovationalpublishers.com/Journal/ijnmi

ISSN No: $2656-4656$

DOI: 10.31690/ijnmi.2020.v05i02.001 not adapted to the new demands put on it to work at NEAR in a new visual environment for extensive hours and in stressful environments. Working at a computer gets even more difficult as you get older. That's because the lens of your eye becomes less flexible. ${ }^{[1]}$

Computers have become an indispensable part of modern life. Working for long hours in front of the computer is no longer confined to the office. Computers are now extensively used in schools and at home as well. With increased popularity of notebooks, tablets, smartphone's, and e-book readers, the use of digital devices is no longer only limited to desktops. People use digital display devices for work, web surfing, social networking, and playing video games. In this techno age, children as young as 2 years are given touch screen devices like iPads to play and learn with. Professional video game

Address for Correspondence:

Ms. A. Devika, Department of Medical-Surgical Nursing, Bharati Vidyapeeth College of Nursing, Navi Mumbai, Maharashtra, India. E-mail: devii_11@yahoo.in

This is an open-access journal, and articles are distributed under the terms of the Creative Commons Attribution Noncommercial Share Alike 4.0 License, which allows others to remix, tweak, and build upon the work non-commercially, as long as appropriate credit is given and the new creations are licensed under the identical terms 
players in South Korea are known to spend as long as $18 \mathrm{~h} /$ day in front of their screens at a stretch. These accoutrements of modern living may give rise to a number of visual and ophthalmic problems collectively called the computer vision syndrome (CVS). ${ }^{[2]}$

Computers have made things so much fast and simple but has brought with them new problems related to health and vision. Using computers for long hours, put repetitive stress on body, muscles, and joints, especially to eyes. Problems related to eyes affect all those who spend a significant time working with computers. There are many professionals who spend most of their time in front of computer screen are at risk of CVS. ${ }^{[3]}$

Computer is a man-made machine which faithfully follows man-given orders and shortly gives man-wanted result. In the present world, inventions of computers recorded new heights in technological advancement. It is because of these improvements that life has become so easy and comfortable. A new innovation in the field of science and technology and other areas has transpired to be a gateway for progressive development of a nation and also for entire human civilization. ${ }^{[4]}$

CVS is similar to other repetitive stress injuries at work. It occurs when you are carrying out the same motion over and over again. Just like those other repetitive stress injuries, CVS can get worse the longer you continue the activity. Working at a computer requires that the eyes continuously focus, move back and forth, and align with what you are seeing. You may have to look down at papers and then back up to type, and the eyes have to accommodate to changing images on the screen to create a clear picture for the brain to interpret. All of these functions require a lot of effort from eye muscles. Working on a computer is more challenging to your eyes than reading a book or piece of paper because a computer screen also adds the elements of screen contrast, flicker, and glare. Computer eye problems are more likely to occur if you already have an eye problem such as nearsightedness or astigmatism or if you need glasses but do not wear them or wear the wrong prescription for computer use. ${ }^{[5]}$

The American Optometric Association defines CVS as a group of eye and vision-related problems that occur due to prolonged computer usage. The ocular discomfort appears to increase with the amount of computer usage. Up to $90 \%$ of computer users may experience visual symptoms such as blurred vision, eyestrain, headaches, ocular discomfort, dry eye, and diplopia. In addition, there may be neck and shoulder pain. Dry eye is intimately related to CVS as either cause or effect. Contributing factors may be reduced rate of blinking, environmental factors (air conditioners, heating, and low humidity), and corneal exposure due to higher gaze angle in desktop monitor viewing, a computer screen is different than viewing a typewritten or printed page. Often, the letters on a computer screen are not as precise or sharply defined, the level of contrast of the letters to the background is reduced, and the presence of glare and reflections on the screen may make viewing more difficult. ${ }^{[3]}$

\section{Statement}

"A study to assess the knowledge of CVS among bank employees working in selected banks at Mangalore with the view to develop self-instruction module."

\section{Objectives}

The objectives of the study were as follows:

- Assess the knowledge of bank employees regarding CVS

- Find out the association between knowledge about CVS and selected demographic variables.

\section{Hypothesis}

The hypothesis will be tested at 0.05 level of significance.

- $\mathrm{H}_{1}$ : There will be a significant association between the levels of knowledge regarding CVS among bank employees with demographic variable.

\section{Materials and Methods}

\section{Study design and setting}

Non-experimental descriptive design was used for this study. The study was conducted in the selected banks, at Mangalore.

\section{Sampling size and sampling methods}

In this study, population comprise 50 bank employees working in banks at Mangalore. Purposive sampling technique was used for the selection of subjects. Who are sensitized to any research studies on CVS in the past 3 months and who are physically and psychologically not fit are excluded from the study.

\section{Data collection tool and technique}

Self-administered questionnaire was used for collecting relevant information from the bank employees regarding baseline pro forma and knowledge of CVS. The tools were divided into two parts.

- Part I: Baseline pro forma to elicit socio-baseline information of the samples and it consists of items from 1 to 12

- $\quad$ Part II: Structured knowledge questionnaire with 30 items regarding knowledge of CVS. The investigator administered the questionnaire to the samples after obtaining consent and instructed them to put the $(\sqrt{ })$ to the correct responses, and scored as "1" for correct answer and " 0 " for wrong answer.

\section{Statistical analysis}

Statistical analysis was done using descriptive and inferential statistics. Data were collected, revised, coded, analyzed, and tabulated using number and percentage distribution.

\section{RESULTS}

The results have been organized and presented in three parts:

\section{Part I: Description of baseline variables}

This part deals with description of the baseline characteristics of 50 samples. Data were analyzed using descriptive statistics 
and are summarized in terms of frequency and percentage, which is presented in Table 1.

\section{Part II: Assessment of knowledge regarding CVS among bank employees}

To assess the level of knowledge of bank employees, the percentage scores were graded arbitrarily as follows:

\begin{tabular}{lc}
\hline Interpretation of knowledge & Score \\
\hline Adequate & $21-30$ \\
Moderately adequate & $11-20$ \\
Inadequate & $1-10$ \\
\hline
\end{tabular}

Data, in Table 2, show that $70 \%$ of the bank employees had moderate level of knowledge and 30\% had inadequate level of knowledge.

Data in Table 3 reveal that the overall mean percentage of the bank employee's knowledge regarding CVS is $37.46 \%$ with mean 11.24, median 25.5, and SD is 2.58 .

\section{Part III: Association between knowledge of bank employees and baseline variables}

To find the association between the knowledge and selected baseline variables of bank employees, the following null hypothesis was formulated against research hypothesis. The hypothesis was tested using Chi-square test at 0.05 levels of significance.

Table 1: Frequency and percentage distribution of bank employees according to their baseline characteristics $(n=50)$

\begin{tabular}{|c|c|c|}
\hline Variable & Frequency & Percentage \\
\hline \multicolumn{3}{|l|}{ Age (in years) } \\
\hline $20-30$ & 7 & 14 \\
\hline $31-40$ & 11 & 22 \\
\hline $41-50$ & 26 & 52 \\
\hline $51-60$ & 6 & 12 \\
\hline \multicolumn{3}{|l|}{ Gender } \\
\hline Male & 36 & 72 \\
\hline Female & 14 & 28 \\
\hline \multicolumn{3}{|l|}{ Educational qualification } \\
\hline Undergraduate & 9 & 18 \\
\hline Graduate & 35 & 70 \\
\hline Postgraduate & 6 & 12 \\
\hline Any other qualification (specify) & - & - \\
\hline \multicolumn{3}{|l|}{ Years of work experience in computer } \\
\hline Below 1 year & 3 & 6 \\
\hline $1-5$ years & 10 & 20 \\
\hline $6-10$ years & 28 & 56 \\
\hline Above 10 years & 9 & 18 \\
\hline \multicolumn{3}{|l|}{ Do you have any eye/vision problem? } \\
\hline Yes & 27 & 54 \\
\hline No & 23 & 46 \\
\hline \multicolumn{3}{|l|}{ Are you wearing spectacles? } \\
\hline Yes & 32 & 64 \\
\hline No & 18 & 36 \\
\hline \multicolumn{3}{|c|}{ Do you take break in between your continuous work on computer? } \\
\hline Yes & 18 & 36 \\
\hline No & 32 & 64 \\
\hline \multicolumn{3}{|l|}{ Do you practice relaxation techniques? } \\
\hline Yes & 2 & 4 \\
\hline No & 48 & 96 \\
\hline \multicolumn{3}{|c|}{ Do you use antiglare computer screen at work? } \\
\hline Yes & 1 & 2 \\
\hline No & 49 & 98 \\
\hline
\end{tabular}

$\mathrm{H}_{0}$ : There will be no significant association between the level of knowledge and selected baseline variables among bank employees.

The data presented in Table 4, which show that eye problem in the baseline variable has significant association with the level of knowledge of bank employees. All the other baseline variables do not have significant association between the knowledge and selected baseline variables among bank employees. Hence, the null hypothesis is rejected and research hypothesis is partially accepted.

\section{Discussion}

In accordance with 50 samples, it is observed that the highest percentage $(52 \%)$ of the samples was from the age group of $41-50$ years. About $72 \%$ of the samples were male. About $70 \%$ of the samples are graduates. Highest percentage $(56 \%)$ of the samples has 6-10 years of work experience. About $54 \%$ of the samples have eye/vision problem. About $64 \%$ of the samples were using spectacles. About $64 \%$ of the samples were not taking break in between computer work. About $96 \%$ of samples were not practicing any relaxation technique. About $98 \%$ of samples not using antiglare computer screen at work.

Table 2: Frequency and percentage distribution of existing knowledge of bank employees regarding computer vision syndrome $(n=50)$

\begin{tabular}{lcc}
\hline Level of knowledge & Frequency (f) & Percentage \\
\hline Adequate & 0 & 0 \\
Moderately adequate & 35 & 70 \\
Inadequate & 15 & 30 \\
\hline
\end{tabular}

Table 3: Mean, SD, and mean percentage of level of knowledge of bank employees regarding computer vision syndrome

\begin{tabular}{lccc}
\hline Mean & Median & Mean \% & SD \\
\hline 11.24 & 25.5 & $37.46 \%$ & 2.58 \\
\hline
\end{tabular}

Table 4: Association of knowledge level of bank employees with the selected baseline variables $(n=50)$

\begin{tabular}{lcccc}
\hline Baseline variables & df & $\begin{array}{c}\text { Calculated } \\
\text { value }\left(\chi^{2}\right)\end{array}$ & $\begin{array}{c}\text { Table } \\
\text { value }\end{array}$ & Inference \\
\hline Age & 3 & 1.319 & 7.82 & $\mathrm{NS}$ \\
Gender & 1 & 0.017 & 3.84 & $\mathrm{NS}$ \\
Education & 2 & 3.61 & 5.99 & $\mathrm{NS}$ \\
Year of work experience & 3 & 2.986 & 7.82 & $\mathrm{NS}$ \\
Eye problem & 1 & 9.971 & 3.84 & $\mathrm{~S}$ \\
Use of spectacles & 1 & 1.057 & 3.84 & $\mathrm{NS}$ \\
Break in between computer & 1 & 0.808 & 3.84 & $\mathrm{NS}$ \\
work & & & & $\mathrm{NS}$ \\
Practice of relaxation & 1 & 0.892 & 3.84 & \\
technique & & & & $\mathrm{NS}$ \\
Use of antiglare computer & 1 & 0.436 & 3.84 & \\
screen & & & &
\end{tabular}

NS: Not significant, S: Significant 
The findings of the present study reveal that the mean percentage of total knowledge score was $37.46 \%$ with mean 11.24, median 25.5, and SD 2.58. Most (70\%) of the samples had moderate knowledge; about $30 \%$ of them had inadequate knowledge regarding CVS.

A quantitative, descriptive, cross-sectional study was conducted to determine the level of knowledge and extent of CVS among computer users at the Securities and Exchange Commission (SEC), Abuja, Nigeria. Structured questionnaire was administered to 100 computer users aged between 18 and 40 years. The findings showed that $40 \%$ of the participants were aware of CVS; of which $27 \%$ had knowledge of the disorder. CVS was common among the employees, $74 \%$ of the respondents experienced at least one symptom of CVS. Headache and eyestrain were the most common symptoms of CVS among the studied population. The study concluded that there is a serious knowledge gap about CVS in the studied population which suggests a similar knowledge gap in the general population. ${ }^{[6]}$

Above findings are supported by study conducted to assess the knowledge and practices of computer use in students studying in different universities in Malaysia, conducted by the Department of Ophthalmology, Faculty of Medicine, International Medical University, Malaysia. A cross-sectional, questionnaire survey method was used to collect the data. A total number of 795 students, aged between 18 and 25 years, from five universities in Malaysia were surveyed. Result of the study shows that the prevalence of symptoms of CVS (one or more) was found to be $89.9 \%$; the most disturbing symptom was headache $(19.7 \%)$ followed by eye strain (16.4\%). Students who used computer for more than $2 \mathrm{~h}$ /day experienced significantly more symptoms of CVS $(P=0.0001)$. Looking at far objects in-between the work was significantly $(P=0.0008)$ associated with less frequency of CVS symptoms.
The use of radiation filter on the screen $(P=0.6777)$ did not help in reducing the CVS symptoms.

\section{Conclusion}

About $90 \%$ of university students in Malaysia experienced symptoms related to CVS, which was seen more often in those who used computer for more than $2 \mathrm{~h}$ continuously per day. ${ }^{[7]}$

The researcher concluded that the knowledge of CVS is inadequate among the computer users and thus there is a need to improve the knowledge through education and organizing programs.

\section{References}

1. Kozier B. Fundamentals of Nursing Concepts, Process and Practice. $5^{\text {th }}$ ed. Philadelphia, PA: Benjamin Cunnings Publishing Company; 1995. p. 800 .

2. Barthakur R. Computer vision syndrome. Intern J Med Update 2013;8:1-2.

3. Lemons N. Computer Impact on Education, Business, Entertainment, History and Future and the Private Sector. Available from: http://www. english.ttu.edu/course/NKCHome.html. [Last accessed on 2015 Feb 20].

4. Computer vision syndrome. Available from: http://www.en.wikipedia. org/wiki/Computer_vision_syndrome. [Last accessed on 2014 Oct 09; Last accessed on $2015 \mathrm{Feb} 18]$.

5. American Opthalmetric Association. Signs and Symptoms of Computer Vision Syndrome. Available from: http://www.aoa.org/patients-andpublic/caring-for-your-vision/protecting-your-vision/computer-visionsyndrome?sso=y. [Last accessed on $2014 \mathrm{Feb} 12]$.

6. Available from: https://www.pdfs.semanticscholar.org/069e/868cb390e 8fa1 fa37c74465d4ff2937cb84c.pdf [Last accessed on 2013 Sep 05].

7. NEPJOPH. Available from: https://www.researchgate.net/ publication/258202984_Computer_vision_syndrome_A_study_of_ knowledge_and_practices_in_university_students.

How to cite this article: Devika A. A Study to Assess the Knowledge on Computer Vision Syndrome among Bank Employees Working in Selected Banks at Mangalore with the View to Develop Self-Instruction Module. Int J Nurs Med Invest. 2020;5(2):11-14. 